\title{
Psoriasis and Alcohol Abuse
}

Captain G E Vincenti

MB BS, RAMC, SHO in Psychiatry

Dr S M Blunden

MBBS, MRCPsych, Consultant Psychiatrist

*Queen Elizabeth Military Hospital, Woolwich

SUMMARY: The clinical association of psoriasis with alcohol abuse is explored through three recent cases seen in the Alcohol Treatment Unit (ATU) at Queen Elizabeth Military Hospital (QEMH), Woolwich.

\section{Introduction}

The association between psoriasis and alcohol abuse is generally mentioned only in the small print of standard texts, and is quoted only in relation to liver damage and the implication thereof for the use of methotrexate therapy to control the psoriasis. Delaney and Leppard ${ }^{1}$ found no association between liver disease, alcohol consumption, and psoriasis in a small study. However, Chaput et $\mathrm{al}^{2}$ in a very large study found that whilst there was indeed no link between psoriasis and liver disease, there was a signficant association between psoriasis and alcohol abuse (disregarding the presence or absence of alcoholic liver disease) at the level of $\mathrm{P}<0.001$.

The Alcohol Treatment Unit (ATU) at QEMH Woolwich is permanently busy because it provides a global service, so that all complications of alcohol abuse are seen regularly. In recent times these complications have tended to occur in clusters, and we report one such series relating alcohol to psoriasis.

For the purposes of clarity, it is worth stating that 1 unit of alcohol is taken as the equivalent of 1 half pint of beer, 1 glass of wine, or 1 Imperial measure of a spirit. The World Health Organisation advise that regular consumption of 8 units of alcohol per day for a man, or 5 units for a woman, poses particular risks to health through the dangers of alcohol abuse. The risk of delirium tremens begins after regular consumption of 12 units of alcohol per day.

\section{Case 1}

Sgt X was a 40 year old NCO in a supporting arm who was transferred from BMH Hannover, Command Psychiatric Unit, having presented in BAOR to his Unit Medical Officer complaining of being unable to cope. His regular alcohol consumption was 6 units at lunch and 10 units in the evening, although in the period leading up to his admission this had increased dramatically. He had suffered from guttate psoriasis intermittently since 1978 , and he had himself noticed a close link between his alcohol intake and the activity of his skin condition. On arrival in Hannover, he was placed on $0.5 \%$ Dithranol cream and Polytar bath oil and shampoo. He also

* Duchess of Kent's Military Hospital, Catterick required intravenous Parentrovite and oral Chlormethiazole as the standard detoxification regime. His liver function tests were normal. On arrival at QEMH Woolwich he was still virtually covered with lesions of guttate psoriasis. Although he had had similar antipsoriatic medication in the past, he reported that after 6 weeks of hospital enforced abstinence, his psoriasis had never been better.

\section{Case 2}

Major $\mathrm{Y}$ was a 46 year old officer in a supporting arn admitted to the ATU at QEMH Woolwich in acute alcohol withdrawal. His regular consumption was welf over 1 bottle of whisky per day together with 6 cans of beer (approx 42 units of alcohol per day). He requirech. the standard detoxification regime. He had suffere from extensive plaque psoriasis for 15 years, and this had come on shortly after a very traumatic road accident. Numerous dermatological treatments had been tried over the years including methotrexate therapy. Towards the end of 1985, a full blood count was taken by a locum dermatologist in preparation for beginning methotrexate therapy again. He was noted to have a mean cell volume of $104 \mathrm{fl}$. The dermatologist received a positive reply when enquiring about alcohol consumption, and went on to tell Major Y that he should cut down or "he would run into difficulties in 5 years or so". He therefore saw a hypnotist who succeeded in stopping him drinking for a period of 5 weeks, during which his psoriasis virtually cleared. However, on relapsing into binge drinking again, the psoriais recurred extensively and he had active psoriasis affecting his nails, scalp and the skin of his arms, legs, trunk, back, abdomen and buttocks on emergency admission to QEMH Woolwich. During his 8 weeks' stay on the ATU, his skin improved with only standard topical therapy and alcohol abstinence. Three weeks after discharge, he relapsed into pathological drinking again precipitated by the unexpected and tragic death of a close relative. On admission after only 1 week's heavy drinking, his skin was severely affected once more. With abstinence and the same topical therapy, however, the psoriasis subsided. Throughout this period his liver function tests were normal. 
Case 3

Sgt $\mathrm{Z}$ was a 27 year old NCO from a combat arm, who was admitted from the Command Psychiatric Unit at BMH Hannover. He made his own way across the Channel and had drunk steadily on the journey, and he therefore required his second detoxification regime in one month when he arrived at QEMH Woolwich. His average consumption was a litre of vodka a day (approx 40 units). He had been consuming alcohol at this level for well over one year. He had suffered from facial psoriasis for many years, and like Case 1, he also had made a connection for himself between his alcohol consumption and the activity of his skin condition. His psoriasis improved in the ATU without recourse to any dermatological medication. Unfortunately, Sgt Z has since gone AWOL from the ATU and has been lost to follow-up. His admission liver function tests were abnormal with an asparate amino transferase of 66 International Units/l (normal limits 10-40 International Units/l), alanine amino transferase of 54 International Units/l (normal limits 10-40 International Units/1), bilirubin $55 \mu \mathrm{mols}$ (normal less than $17 \mu \mathrm{mol} / \mathrm{l}$ ), globulin $66 \mathrm{gm} / 1$ (normal limits $17-42 \mathrm{gm} / \mathrm{l}$ ) and glutamy L transferase GT of 62 International Units/l (normal limits 1048 International Units/l). These were all normal at the time of absconding.

\section{Comment}

In all three cases the clinical link between alcohol consumption and psoriasis seems clear, and in Cases 1 and 2 at least, there is no question of concomitant liver disease. In Cases 1 and 2 the improvement with abstinence from alcohol was obviously helped by dermatological intervention at the same time, something that was not needed in Case 3. The mechanism whereby alcohol abuse leads to a flare up in psoriatic activity is not clear. Certainly Major $\mathrm{Y}$ reported that when drinking at his maximum, he did not have the motor co-ordination to apply cream accurately or even the will-power to bother, but this cannot be the total explanation because Sgt Z (Case 3) improved without specific dermatological treatment, and Major $Y$ (Case 2) noted that hypnotherapy induced abstinence led to improvement without the need for dermatological creams. It is not known whether the hypnotist directed attention to his client's psoriasis as well as to his alcohol abuse!

\section{Conclusions}

Whilst it would be ridiculous to label all sufferers of psoriasis as problem drinkers, the association of these two disorders does have some clinical relevance. A drinking history should be specifically obtained in all patients with psoriasis. If a patient with psoriasis comes to the attention of a medical officer in some manner commonly seen amongst alcoholics (i.e. unexplained Basic Fitness Test failure, detention medical, blood alcohol estimation for a drink/driving offence), theno suspicion of alcohol abuse should be high. More importantly, if a patient with previously well controlle psoriasis reports a flare up in his condition, alcoho $\overrightarrow{\mathrm{B}}$ abuse should be considered in the differential diagnosio and blood for mean cell volume estimation and live function test should be taken.

\section{REFERENCES}

1. DELANEY $T$ J. and LePPARD B. Alcohol intake and Psoriasis, Acta Derm Venereol 1974; 54: 237-238.

2. Chaput J C et al. Psoriasis Alcohol and Liver Disease. $\mathrm{Br}$ MedJ. 1985;291:25.

\section{THE UNIVERSITY OF LONDON OFFICERS TRAINING CORPS}

The University of London Officers Training Corps is presently forming a Regimental Association. The main objective of the Association is to re-unite all members, both past and present of ULOTC, primarily through social events. Should readers who are ex-members of ULOTC or have served with ULOTC be interested in becoming members or have any further enquiries please send a large stamped addressed envelope to:

The Secretary

ULOTC Regimental Association

Yeomanry House

Handel Street

London, W1N 1NP 